\title{
UNIVERSIDADE POPULAR NO BRASIL E RELAÇÕES ÉTNICO-RACIAIS: O CASO DA UNIVERSIDADE DA INTEGRAÇÃO INTERNACIONAL DA LUSOFONIA AFRO-BRASILEIRA (UNILAB)
}

POPULAR UNIVERSITY IN BRAZIL AND ETHNIC-RACIAL RELATIONS:

THE CASE OF THE UNIVERSITY OF INTERNATIONAL INTEGRATION OF AFROBRAZILIAN LUSOPHONY (UNILAB)

UNIVERSIDAD POPULAR EN BRASIL Y RELACIONES ÉTNICO-RACIALES:

EL CASO DE LA UNIVERSIDAD DE LA INTEGRACIÓN INTERNACIONAL DE LA LUSOFONÍA AFRO-BRASILEÑA (UNILAB)

RESUMO: O presente artigo busca analisar como se configuram, no Brasil contemporâneo, as chamadas universidades populares - categoria que buscaremos aqui definir - e como se inserem, nesta categoria, as questões étnico-raciais, especialmente vinculadas ao processo de educação superior. Para ilustrar essa relação entre universidade popular e questões étnico-raciais, analisaremos o caso da Universidade da Integração Internacional da Lusofonia Afro-Brasileira (UNILAB), verificando aspectos próprios dessa universidade, na correlação com as categorias acima referidas.

PALAVRAS-ChAVE: Ensino superior. Universidade popular. Questões étnico-raciais. UNILAB.

ABSTRACT : This article analyzes how to set up, in contemporary Brazil, popular universities - a category we will seek to define here - and how to fall in this category, ethnic and racial issues, especially related to the higher education process. To illustrate this relationship between popular university and ethnic and racial issues, this article analyzes the case of the Universidade da Integração Internacional da Lusofonia Afro-Brasileira (UNILAB), verifying specific aspects of this university, in correlation with the above categories.

KEYWORDS: Higher education. Popular university. Ethnic and racial issues. UNILAB.

RESUMEN : El presente artículo busca analizar cómo se configuran, en el Brasil contemporáneo, las llamadas universidades populares - categoría que buscaremos aquí definir - y cómo se inserta en esta categoría las cuestiones étnico-raciales, especialmente vinculadas al proceso de educación superior. Para ilustrar esa relación entre universidad popular y cuestiones étnico-raciales, analizaremos el caso de la Universidad de la Integración Internacional de la Lusofonía Afro-Brasileña (UNILAB), verificando aspectos propios de esa universidad, en la correlación con las categorías arriba mencionadas.

PALABRAS CLAVE: Enseñanza superior. Universidad popular. Relaciones étnico-raciales. UNILAB.

Submetido em: 11/06/2017 - Aceito em: 25/06/2017 - Publicado em: 16/10/2017.

\begin{tabular}{l|l|l|l|l|l} 
(C) Rev. Inter. Educ. Sup. & Campinas, SP & v.4 & n.1 & p.112-129 & jan./abr. 2018
\end{tabular}




\section{INTRODUÇÃ̃}

Neste trabalho, discutiremos duas categorias que servirão de ponto de partida às nossas considerações acerca da Universidade da Integração Internacional da Lusofonia AfroBrasileira (UNILAB), a fim de analisar, mais detidamente, o processo de constituição, nesta universidade, de uma educação popular de nível superior, tal como defendemos que tenha ocorrido parcialmente no Brasil dos últimos anos: trata-se das categorias de universidade popular e de questões étnico-raciais. O presente estudo insere-se num projeto mais abrangente, intitulado "Observatório da Universidade Popular no Brasil", financiado pela CAPES, no âmbito do Programa de Mestrado e Doutorado em Educação, sediado na Universidade Nove de Julho. Analisando a configuração das universidades populares no Brasil - aqui ilustradas pelo caso da UNILAB -, com destaque para as questões étnico-raciais e sua correlação com o ensino universitário, acreditamos contribuir para uma mais profunda reflexão acerca das atuais políticas públicas voltadas à educação superior, além de promover, a partir dessas reflexões, um maior empoderamento do alunado afrodescendente, agindo no sentido de levá-lo a alcançar maior conscientização de seu papel histórico na sociedade brasileira.

Estudos mais ou menos recentes sobre a universidade brasileira apontam para o que podemos chamar de crise do ensino superior, uma crise que se configura a partir, de um lado, do esgotamento do atual modelo de universidade pública, que se torna cada vez mais corporativista, e, de outro lado, uma expansão da universidade privada, que assume cada vez mais um feitio mercantilista. Muito dessa crise, há que se ressaltar, resulta de condições históricas que determinaram o surgimento e a consolidação de um modelo universitário "híbrido" na América Latina, além de se tratar, em última instância, de um modelo "transplantado" da Europa e aqui aclimatado em condições, no mínimo, adversas. Estudando o que denomina modelos de ocasião, para se referir aos modelos universitários atualmente prevalentes no Brasil, Valdemar Sguissardi (2011) lembra que, além desse processo de hibridização/transplantação vivido por nosso ensino universitário, houve, no século XX, uma adaptação do modelo norte-americano, culminando, a partir dos anos oitenta e noventa, num modelo neoliberal de educação superior, caracterizado, entre outras coisas, pela valorização da profissionalização e da competitividade.

Essa é, aliás, uma crítica que já se vinha fazendo há algum tempo, seja de uma maneira difusa, em que se condenam o excesso de especialização e a função utilitária da atividade acadêmica (BUARQUE, 1994), seja de modo mais sistemático, em que se rejeita o caráter elitista de uma universidade visceralmente vinculada às profissões liberais e afins (FERNANDES, 1975). Por fim, numa crítica mais atualizada, investe-se contra a transnacionalização do mercado universitário, procurando demonstrar que a educação é uma 
mercadoria como qualquer outra e defendendo sua privatização, desregulação e mercadorização (SANTOS, 2010).

Embora negativo, esse é um quadro que se mantém extremamente atual no Brasil contemporâneo, apesar de ser possível reconhecer alguns avanços pontuais, no âmbito da educação superior - sobretudo em termos de conquistas vinculadas às noções de equidade e igualdade -, a partir dos governos Fernando Henrique e Lula (SANTOS; SILVA, 2012). Consequência imediata desses avanços, foi o surgimento de algumas instituições de ensino superior, em especial determinadas universidades públicas federais, que se propuseram a uma renovação da educação universitária brasileira, a que aqui denominamos universidade popular e da qual buscaremos esboçar, na sequência, uma tipologia inicial.

Do ponto de vista metodológico, nossa pesquisa adota uma perspectiva qualitativa, que, de modo geral, apresenta a vantagem de assentar-se numa concepção mais dinâmica entre o observador/observado e a realidade circundante (CHIZZOTTI, 1991), privilegiando a técnica da pesquisa bibliográfica e documental (LAKATOS; MARCONI, 2001), e optando por uma estratégia metodológica (MASON, 2002) que tem no comparatismo bibliográfico seu principal fundamento.

Consideramos, nesse sentido, pelos menos dois recortes fundamentais: primeiro, a consideração do conceito de universidade popular aqui empregado aproxima-se daquele forjado, num primeiro momento, no contexto do Fórum Social Mundial e que apresenta como um de seus principais fundamentos a assunção de uma prática que se destina à produção de uma conhecimento contra-hegemônico, como resistência à globalização neoliberal; segundo, a observação dos pressupostos e dos desdobramentos direta ou indiretamente relacionadas à Lei 10.639, de 2003, que define a obrigatoriedade do ensino de história e cultura africana e afro-brasileira nos ensinos fundamental e médio.

\section{PARA UMA TIPOLOGIA DA UNIVERSIDADE POPULAR NO BRASIL}

Para uma tipologia do que vimos aqui chamando, até agora, de universidade popular, é necessário, antes de mais nada, pensarmos numa categoria mais abrangente, qual seja, a de educação popular, sobretudo aquela advinda do legado freiriano. E, sobretudo, ao associarmos essa categoria às questões étnico-raciais, tal como propusemos aqui desde o início, não podemos prescindir da ideia de resistência, que se verifica em pelo menos dois dos fundamentos da educação popular: um processo geral de reconstrução do saber social (educação da comunidade) e um trabalho político de luta por transformações sociais e justiça social. Com efeito, como demonstram Brandão \& Assumpção (2009), remetendo-nos à memória de algumas das reivindicações do Movimento Negro e dos projetos de 
popularização da educação junto à população afrodescendente, a educação popular promove a passagem de uma educação para o povo para uma educação que o povo cria, isto é, uma educação por meio da qual "ele [o povo] não se veja apenas como um anônimo sujeito da cultura brasileira, mas como um sujeito coletivo da transformação da história e da cultura do país" (p. 33). Em outros termos, "a educação popular não é uma atividade pedagógica para, mas um trabalho coletivo em si mesmo, ou seja, é o momento em que a vivência do saber compartilhado cria a experiência do poder compartilhado" (p. 35).

Esse princípio está, como sugerimos, na base do pensamento freiriano acerca da educação, mas tem também repercussões na própria consideração de Paulo Freire do processo (e do projeto) colonizador do qual a população negra - dentro e fora do Brasil - foi sua maior vítima. De fato, nas palavras de Freire (1977), tratando mais especificamente de sua experiência com a população de Guiné-Bissau, mas sem dúvida alguma podendo ser adaptadas para o contexto brasileiro,

\begin{abstract}
a ideologia colonialista, procurava incutir nas crianças e nos jovens o perfil que deles fazia aquela ideologia. $\mathrm{O}$ de seres inferiores, incapazes, cuja única salvação estaria em tornar-se 'brancos' ou 'pretos de alma branca'. Daí o descaso que essa escola necessariamente teria de ter por tudo o que dissesse de perto aos nacionais, chamados de 'nativos'. Mais do que descaso, a negação de tudo o que fosse representação mais autêntica da forma de ser dos nacionais: sua história, sua cultura, sua língua (p. 21).
\end{abstract}

É nesse sentido, ainda, que merece destaque a reflexão de Paulo Freire (2010) acerca do lugar que o oprimido ocupa na sociedade, considerando - aqui, no contexto específico do papel que as populações afrodescendentes, historicamente oprimidas por um processo de modernização estrutural da sociedade de natureza excludente (FERNANDES, 2007) - a necessidade de uma busca constante da liberdade.

O conceito de universidade popular aqui empregado aproxima-se, ainda, daquele forjado, num primeiro momento, no contexto do Fórum Social Mundial e que apresenta como um de seus principais fundamentos a assunção de uma prática que se destina à produção de um conhecimento contra-hegemônico (GADOTTI, 2003). Com efeito, semelhante princípio encontra-se na base da concepção, mais genérica, de educação popular como forma de resistência e oposição a uma epistemologia hegemônica. Desse modo, a ideia - a nosso ver totalmente factível - de uma universidade popular dentro desse enquadramento teórico-prático supre, parcialmente, a já aventada necessidade de renovação da teoria social e política princípio, aliás, previsto no citado Fórum Social Mundial, que capitaneou, nesse novo século, os movimentos de resistência à globalização neoliberal (SADER, 2005) - tal como propõe Boaventura Sousa Santos (2007) ao destacar seu papel no amplo processo de renovação da teoria e reinvenção da emancipação sociais. Em termos mais práticos, Naomar Almeida-Filho (2012), ao estudar o que chama de dilemas da universidade brasileira no contexto da internacionalização, salienta a necessidade de renovação da universidade no Brasil,

\begin{tabular}{l|l|l|l|l|l} 
(C) Rev. Inter. Educ. Sup. & Campinas, SP & v.4 & n.1 & p.112-129 & jan./abr. 2018 \\
\hline
\end{tabular}


propondo, entre outras coisas, a adoção de ciclos de formação, regime que tem sido parcialmente adotado no país, por exemplo, na Universidade Federal do ABC, em São Paulo, e na Universidade Federal da Bahia.

Pretendemos, em especial nesta quadra de nosso trabalho, contribuir para uma melhor definição do conceito de universidade popular, com vista a uma tipologia inicial desse conceito, em especial no contexto brasileiro de instituições públicas de ensino superior, empregando, para tanto, um procedimento metodológico que consiste na prospecção de quatro estudos bibliográficos - que abordam desde a educação popular e aspectos relacionados à avaliação docente e discente, passando por questões de internacionalização e política de inclusão no ensino superior -, sempre numa perspectiva em que está subentendida a comparação/contraste com concepções supostamente tradicionais de universidade pública. Faz parte, igualmente, desse procedimento, a consideração de três vertentes analíticas que se configuram, na verdade, como propriedades fundamentais da educação superior: uma epistemologia - que se constitui num conjunto de princípios abstratos e teóricos, atuando como fundamentação cognitiva da universidade popular -, que se desdobra em uma metodologia - representando princípios concretos e práticos, entendidos como suas necessidades e potencialidades -, que, finalmente, se traduz em determinadas políticas compostas por procedimentos e ações empiricamente aplicáveis. Por fim, os estudos bibliográficos que articulamos aqui são os seguintes: Gadoti; Stangherlim (2013), Benincá; Santos (2013), Loss; Kratochvil (2014) e Romão; Loss (2014).

Do ponto de vista epistemológico, uma universidade popular deve-se voltar, como afirmam Loss \& Kratochvil (2014), para a "constituição de saber e ações contra-hegemônicos" (p. 361), que se traduz tanto no conceito de diversidade quanto no de nova racionalidade; tais conceitos atuam em conjunto com as ideias de emancipação, de liberdade e de modelo alternativo de conhecimento e desenvolvimento. Ampliando um pouco essa perspectiva, o quadro abaixo indica essas e outras categorias apontadas pelos autores como necessárias à constutição epistemológica da universidade popular:

Quadro 1. Base tipológica: fundamentação cognitiva

\begin{tabular}{|l|l|}
\hline \multicolumn{2}{|c|}{ epistemologia (fundamentação cognitiva) } \\
\hline Categorias & \multicolumn{1}{|c|}{ Fontes } \\
\hline Diversidade & $\begin{array}{l}\text { 1. "diversidade de vozes e de saberes coletivos" (LOSS \& KRATOCHVIL, 2014, p. } \\
360) ;\end{array}$ \\
& $\begin{array}{l}\text { 2. "conhecimento e [...] consciência reflexiva sobre diferentes culturas e classes } \\
\text { sociais" (LOSS \& KRATOCHVIL, 2014, p. 360); } \\
\text { 3. "Uma universidade popular é uma universidade sem fronteiras, aberta à diversidade, } \\
\text { transversal, sem cercas ou poder acadêmico" (GADOTI \& STANGHERLIM, 2014, p. } \\
\text { 44). }\end{array}$ \\
\hline $\begin{array}{l}\text { Racionalidade } \\
\text { contra-hegemônia }\end{array}$ & $\begin{array}{l}\text { 2014, p. 361); } \\
\text { 2. "nova racionalidade [que possa] romper com a reprodução ideológica da } \\
\text { racionalidade instrumental"; "ruptura com o modelo de racionalidade instrumental" }\end{array}$ \\
\hline
\end{tabular}




\begin{tabular}{|l|l|}
\hline & (LOSS \& KRATOCHVIL, 2014, p. 370). \\
\hline Outras: emancipação, & 1. "emancipação" e "dimensão emancipatória" do(s) sujeito(s) (LOSS \& \\
liberdade, & KRATOCHVIL, 2014, p.369); \\
humanização, & 2. "A educação deveria ser a promotora por excelência do diálogo, da participação e da \\
alternativa etc. & $\begin{array}{l}\text { liberdade dos sujeitos na construção da identidade individual e coletiva" (ROMÃO \& } \\
\text { LOSS, 2014, p. 46); } \\
\text { 3. "O ato educativo deveria proporcionar condições favoráveis às pessoas para a busca } \\
\text { da humanização e não somente da capacitação" (ROMÃO \& LOSS, 2014, p. 46); } \\
\text { 4. "projeto nacional de desenvolvimento alternativo ao modelo neoliberal" (BENINCÁ } \\
\text { \& SANTOS, 2014, p. 74). }\end{array}$ \\
\hline
\end{tabular}

Fonte: autor

Do ponto de vista da metodologia que a universidade popular deve adotar, os autores estudados destacam três atitudes, de natureza mais prática, que podem ser resumidas numa prática pedagógica específica, de natureza popular (o que implica, por exemplo, fatos bem concretos, como a elaboração de uma determinada grade curricular, posteriormente explicitada nas políticas educacionais); na valorização da classe popular como público ideal dessa universidade; e no agenciamento de princípios e valores próprios do que se convencionou chamar de educação popular. Como se percebe, metodologicamente falando, as práticas pertinentes à universidade popular voltam-se, todas elas, para a caracterização/afirmação de um saber popular, definido no âmbito de uma classe social marcada, historicamente, pela exclusão.

O quadro abaixo, mais uma vez, busca exprimir essa realidade de modo mais sistematizado:

Quadro 2. Base tipológica: metodologia

\begin{tabular}{|c|c|}
\hline \multicolumn{2}{|r|}{ metodologia (modelos de atuação) } \\
\hline universo & fontes \\
\hline Saber popular & $\begin{array}{l}\text { 1. "práxis pedagógica [voltada para o desenvolvimento do] processo dialético entre o } \\
\text { saber popular e o saber elaborado" (LOSS \& KRATOCHVIL, 2014, p. 366); } \\
\text { 2. "um currículo que requer permanente e disciplinada investigação e reflexão } \\
\text { epistemológica sobre os saberes coletivos em relação dialética com os saberes } \\
\text { científicos" (LOSS \& KRATOCHVIL, 2014, p. 367); } \\
\text { 3. "[dar um novo enfoque aos temas,] para que sejam tratados intertematicamente, } \\
\text { intertransdisciplinarmente e intertransculturalmente" (GADOTI \& STANGHERLIM, } \\
\text { 2014, p. 45). }\end{array}$ \\
\hline Classes populares & $\begin{array}{l}\text { 1. "uma estrutura de inclusão que seja capaz de diminuir a distância entre a } \\
\text { universidade e as classes populares" (LOSS \& KRATOCHVIL, 2014, p. 362); } \\
\text { 2. "IES pública e popular, aberta aos grupos sociais mais excluídos" (LOSS \& } \\
\text { KRATOCHVIL, 2014, p. 363); } \\
\text { 3. "A universidade deve estar aberta para incluir os projetos emergentes da sociedade e } \\
\text { estudá-los cientificamente" (ROMÃO \& LOSS, 2014, p. 47). }\end{array}$ \\
\hline $\begin{array}{l}\text { Educação } \\
\text { conteúdo, } \\
\text { teorias etc. }\end{array}$ & $\begin{array}{l}\text { 1. "Devemos reafirmar os princípios e valores da educação popular e inovar nas } \\
\text { temáticas, nos conteúdos, nas prioridades e nos enfoques" (GADOTI \& } \\
\text { STANGHERLIM, 2014, p. 44); } \\
\text { 2. "criar um referencial teórico e prático que contribua de modo significativo com a } \\
\text { reversão do processo histórico de exclusão social e a instituição de uma praxis } \\
\text { efetivamente transformadora" (BENINCÁ \& SANTOS, 2014, p. 67). }\end{array}$ \\
\hline
\end{tabular}

Fonte: autor

\begin{tabular}{|l|l|l|l|l|l} 
(C) Rev. Inter. Educ. Sup. & Campinas, SP & v.4 & n.1 & p.112-129 & jan./abr. 2018
\end{tabular}


Finalmente, do ponto de vista das políticas a serem adotadas no âmbito da universidade popular, identificamos, na bibliografia consultada, pelo menos cinco ações concretamente propostas, que vão do estabelecimento de uma nova matriz curricular até a implementação de uma estrutura participativa nas instâncias decisórias da universidade. Vejamos, ainda uma vez, um quadro resumitivo dessas propostas:

Quadro 3. Base tipológica: políticas educacionais

\begin{tabular}{|c|c|}
\hline \multicolumn{2}{|r|}{ políticas educacionais (procedimentos) } \\
\hline propostas & Fontes \\
\hline Ingresso & $\begin{array}{l}\text { 1. "Escola pública como única forma de ingresso" (LOSS \& KRATOCHVIL, 2014, p. } \\
\text { 370); } \\
\text { 2. "Direito de ingresso na instituição universitária [...] sob a fórmula do tratamento } \\
\text { desigual aos desiguais" (BENINCÁ \& SANTOS, 2014, p. 54). }\end{array}$ \\
\hline Currículo & $\begin{array}{l}\text { 1. "a partir da matriz curricular, os acadêmicos devem instigar o debate sobre o projeto } \\
\text { político-pedagógico dos cursos de graduação para que contemplem os componentes } \\
\text { curriculares do saber institucionalmente elaborado e considerado como 'erudito' o saber } \\
\text { 'popular'" (ROMÃO \& LOSS, 2014, p. 48). }\end{array}$ \\
\hline $\begin{array}{l}\text { Participação } \\
\text { comunidade }\end{array}$ & $\begin{array}{l}\text { 1. "Estrutura participativa: comunidade interna e externa" (LOSS \& KRATOCHVIL, } \\
2014, \text { p. 363). }\end{array}$ \\
\hline $\begin{array}{l}\text { Círculos } \\
\text { epistemológicos }\end{array}$ & $\begin{array}{l}\text { 1. "encontros problematizadores da realidade com vistas a mobilizar os diferentes } \\
\text { saberes para a identificação, tabulação, análise, interpretação e compreensão dos } \\
\text { problemas, visando à superação deles" (ROMÃO \& LOSS, 2014, p. 47). }\end{array}$ \\
\hline $\begin{array}{l}\text { Projeto político- } \\
\text { pedagógico }\end{array}$ & $\begin{array}{l}\text { 1. "não pode haver universidade popular sem projeto político-pedagógico popular, de } \\
\text { poder popular, entendido como uma práxis, um processo de experimentação e } \\
\text { construção de novas relações sociais não mercantilizadas" (GADOTI \& } \\
\text { STANGHERLIM, 2014, p. 45). }\end{array}$ \\
\hline
\end{tabular}

Fonte: autor

Pelo quadros acima expostos, percebemos que a constituição de uma universidade popular ou de qualquer instituição de ensino superior, seja ela privada ou pública - é, ainda, um desafio, em razão da diversidade e da multiplicidade de propostas e de "valores" necessários à sua efetiva implementação. Embora venham sendo feitos - no âmbito acadêmico - estudos no sentido de revelar os alcances e os limites dos projetos de universidade popular no Brasil, ${ }^{2}$ parece haver, mais ou menos, um concenso de que, para uma universidade ser definida como popular de fato, faz-se necessário, antes de mais nada, que ela se afirme como uma instituição contra-hegemônica (TAVARES, 2013), voltada para um projeto libertário de justiça democrática. Nas palavras de Dominique Bussillet (2012),

Les universités populaires doivent donc se concevoir comme un contre-pouvoir à [une] logique marchande; la connaissance doit être um instrument pour la libération du peuple, et non la renforcement de ses chaînes [...] Il faut lutter pour la conquête d'une éducation populaire, démocratique et libertaire, pour une université populaire ouverte au peuple, au service du peuple, afin de construire une société juste, solidaire et libre (p. 280).

${ }^{2}$ Cf. Alexandre (2015); Romão (2015); Nóbrega (2016) e Silva (2016).

\begin{tabular}{l|l|l|l|l|l} 
(C) Rev. Inter. Educ. Sup. & Campinas, SP & v.4 & n.1 & p.112-129 & jan./abr. 2018
\end{tabular}


Com efeito, trata-se de instituições que, seja por elaborar um Plano de Desenvolvimento Institucional participativo, seja pela gênese histórica de sua constituição, seja ainda pela identidade multiétnica que assumem, entre outros fatores, adquirem, ainda que de forma relativa e dentro de certas restrições e injunções institucionais, um estatuto de universidades populares, categoria que emerge como ponto de partida desse nosso trabalho, mas, ao mesmo tempo, um conceito ainda a se construir no espaço mais largo da pesquisa acadêmica acerca do ensino superior brasileiro.

De qualquer maneira, resumindo o conteúdo dos quadros aqui apresentados e buscando um sentido mais sistêmico às categorias, universos e propostas contidas na bibliografia consultada, podemos dizer que, grosso modo, uma universidade popular deve se configurar como uma instituição de ensino superior caracterizada: a) epistemologicamente, pela diversidade de vozes, saberes e práticas culturais, fundamentada numa racionalidade contrahegemônica e não instrumental e objetivando um sentido amplo de emancipação/humanização do sujeito; b) metodologicamente, pela valorização dos saberes populares e coletivos, abordados numa ampla e constante inter-relação e pela inclusão das classes populares, com base em princípios de uma educação popular; c) politicamente, pela democratização das formas de ingresso na instituição e da participação interna e externa em suas instâncias decisórias e na construção de um projeto político-pedagógico que contemple um currículo e círculos epistemológicos assentados no universo dos saberes e das classes populares.

\section{QUESTÕES ÉTNICO-RACIAIS E EDUCAÇÃO SUPERIOR}

A precariedade da situação educacional do negro no Brasil, fato verificado historicamente, levou o contingente populacional de afrodescendentes ${ }^{3}$ a uma drástica situação de abandono, o que, sem dúvida alguma, se reflete no fato de se computar, entre a população negra, um baixo índice de participação nas universidades brasileiras, fazendo-se necessárias medidas que corrijam as desigualdades de acesso e manutenção desse contingente nas universidades (GUIMARÃES, 2003).

Tanto a legislação específica quanto as ações de políticas públicas voltadas a essa questão resultam, basicamente, do reconhecimento e do combate ao racismo e à discriminação no Brasil, que tem na Constituição Federal de 1988 um de seus marcos fundadores. Semelhante legislação desdobrou-se em diversos projetos de lei, em assinaturas de acordos internacionais,

\footnotetext{
${ }^{3}$ A escolha do termo afrodescendente baseia-se em tradição e proposta construídas por movimentos de base: “em busca de uma designação que contemple todos os negros e negras das Américas, o MN [Movimento Negro] e o MMN [Movimento das Mulheres Negras] do Brasil propuseram o termo Afrodescendentes durante o processo preparatório da III Conferência Mundial contra o Racismo, ocorrida em Durban, África do Sul, de 30 de agosto a 7 de setembro de 2001 [...] É um termo que indica amplo contingente populacional que vive em condições de enorme vulnerabilidade econômica e social, resultantes da ação do racismo e da discriminação racial, ainda que não tenha consciência disso. A expressão tem sido utilizada em diversos programas de ação afirmativa para nomear as pessoas que podem pleiteá-las" (SILVA, 2003, p. 43).
}

\begin{tabular}{l|l|l|l|l|}
\hline (C) Rev. Inter. Educ. Sup. & Campinas, SP & v.4 & n.1 & p.112-129
\end{tabular} jan./abr. 2018 
leis federais e estaduais, criação de secretarias e adoção de programas destinados ao combate ao preconceito e à discriminação racial, além das medidas de reparação e/ou compensação especificamente relacionadas à presença do afrodescendente na universidade.

Como demonstram alguns estudos sobre o ensino universitário no Brasil, de modo geral a educação superior constitui um bem cultural acessível a uma minoria que pertence a classes socialmente favorecidas (VIEIRA, 1989). Percebe-se, contudo, a partir dos marcos regulatórios acima expostos - e de vários outros aqui não citados - uma tendência no sentido de buscar corrigir desvios históricos implantados na sociedade brasileira, adotando-se ações compensatórias dentro de um amplo espectro de políticas públicas direcionadas ao alunado afrodescendente egresso do ensino básico.

Assim, dos fatos e das ações acima expostos, resultaram não apenas políticas públicas destinadas ao acesso e manutenção do afrodescendente na universidade brasileira, mas também uma legislação específica que lhes pudesse conferir sustentação legal. Trata-se do que se convencionou chamar, genericamente, de ações afirmativas, que incluem uma série de ações governamentais, que vão da concessão de bolsas e da preparação pré-vestibular, até financiamento e implementação de estratégias e metodologias de ensino, passando ainda pela instituição de cotas raciais. As ações afirmativas surgem, portanto, como tentativa de correção da situação de contraste entre a composição étnico-racial da sociedade brasileira e a taxa de escolarização da população afrodescendente. Uma simples análise dos dados acerca desse contraste (SILVA, 2009) referenda a situação de distorção que indica um fato inquestionável: a população afrodescendente no Brasil cresce em proporção inversa ao seu acesso aos três níveis da educação (ensino fundamental, ensino médio e ensino superior). A disparidade aumenta consideravelmente de acordo com o nível de modalidade de ensino: é, portanto, no ensino superior que as diferenças entre os contingentes branco e negro se revelam maiores.

Como forma de dirimir disparidades como as apontadas no quadro acima, foi sancionado, em 2002, o Decreto Presidencial 4228/2002, que institui o Programa Nacional de Ações Afirmativas, sob a coordenação da Secretaria de Estado dos Direitos Humanos do Ministério da Justiça, tendo como objetivo, entre outros, a "observância, pelos órgãos da Administração Pública Federal, de requisito que garanta a realização de metas percentuais de participação de afrodescendentes, mulheres e pessoas portadoras de deficiência no preenchimento de cargos em comissão do Grupo-Direção e Assessoramento Superiores" (BRASIL, 2002). Uma outra ação realizada no sentido de valorização do legado cultural africano e afro-brasileiro, bem como de incentivo à maior participação do contingente afrodescendente no quadro educacional brasileiro foi a aprovação da célebre Lei 10.639, de 2003, que define a obrigatoriedade do ensino de história e cultura africana e afro-brasileira nos ensinos fundamental e médio. Na sequência de sua aprovação, as Diretrizes Curriculares Nacionais para a Educação das Relações Étnico-Raciais e para o Ensino de História e Cultura AfroBrasileira e Africana, estabelecidas em 2004 pelo MEC/SEPPIR, assinalaram a necessidade

\begin{tabular}{l|l|l|l|l|l} 
(C) Rev. Inter. Educ. Sup. & Campinas, SP & v.4 & n.1 & p.112-129 & jan./abr. 2018 \\
\hline
\end{tabular}


de formação de professores aptos a ministrar disciplinas relativas aos temas propostos pela referida lei, alertando para o fato de que se deve incluir a

discussão da questão racial como parte integrante da matriz curricular, tanto dos cursos de licenciatura para a Educação Infantil, aos anos iniciais e finais da Educação Fundamental, Educação Média, Educação de Jovens e Adultos, como de processos de formação continuada de professores, inclusive de docentes no Ensino Superior (BRASL, 2004, p. 23).

De qualquer maneira, a despeito de várias iniciativas que se podem verificar, no sentido de promover uma maior participação do afrodescendente na sociedade brasileira, sobretudo por meio de sua inclusão em nosso complexo e excludente sistema educacional, sua inserção no universo do ensino superior é, ainda hoje, limitada e precária, o que torna a emergência de universidades pautadas em princípios fundamentais da educação popular não apenas um imperativo social, mas um direito da população afrodescendente.

O caso da Universidade da Integração Internacional da Lusofonia Afro-Brasileira (UNILAB) é um caso que, por motivos diversos, tende a se tornar emblemático dessa conjuntura.

\section{UNILAB: PROJETO DE UMA UNIVERSIDADE POPULAR}

Pode-se dizer que boa parte da situação em que se encontra o afrodescendente no Brasil, em relação á educação superior, se deve principalmente a dois fatores: uma ideologia educacional pautada na meritocracia e na aptidão "natural" (BISSERET, 1974) e uma prática baseada no modelo neoliberal de ensino superior (SGUISSARDI, 2011), o que acaba por resultar na exclusão sistemática do contingente afrodescendente do ensino universitário.

A questão, aqui, é saber em que medida o surgimento de uma universidade que, a princípio, se afirma - seja pela adoção de práticas e princípios supostamente calcados em valores específicos da educação popular, seja pela constituição de um arcabouço normativo de onde essas práticas e princípios emanam - como uma universidade popular, obtém êxito em corrigir eventuais "desvios" na condução de uma educação, ao mesmo tempo, universal e multicultural, em especial no que diz respeito à participação do alunado afrodescendente no ensino superior.

A Universidade da Integração Internacional da Lusofonia Afro-Brasileira (UNILAB) nasce em 2010 e é instalada em 2011, com o objetivo de ministrar aulas no ensino superior, desenvolver pesquisas nas diversas áreas de conhecimento e promover a extensão universitária, tendo como missão institucional específica formar recursos humanos para contribuir com a integração entre o Brasil e os demais países membros da Comunidade dos Países de Língua Portuguesa (CPLP), especialmente os países africanos, bem como promover o desenvolvimento regional e o intercâmbio cultural, científico e educacional (DIÓGENES; AGUIAR, 2013).

\begin{tabular}{|l|l|l|l|l|l|} 
(C) Rev. Inter. Educ. Sup. & Campinas, SP & v.4 & n.1 & p.112-129 & jan./abr. 2018 \\
\hline
\end{tabular}


A partir de uma série de entrevistas realizadas entre os dias 18 e 20 de março de 2014, no campus de Redenção (CE) ${ }^{4}$ podemos ter uma ideia mais precisa de como alguns propósitos, definidos em documentos institucionais da universidade - e que estabelecem uma relação direta ou indireta com o que aqui vimos chamando de universidade popular - são pensados e/ou praticados no cotidiano da universidade.

Assim, pode-se perceber que, para alguns dos gestores da referida universidade, ela é vista como diferente das chamadas universidades tradicionais, a exemplo das propostas de internacionalização e regionalização que priorizam as relações sul-sul, embora estejam cientes de que a universidade precisa seguir os padrões de avaliação e controle das demais instituições de ensino superior, tornando difícil a conciliação entre uma proposta alternativa e uma legislação formal de natureza tradicional. Essa realidade, ressalva alguns dos entrevistados, não dispensa uma atitude por parte de uma parcela do corpo gestor da universidade que acaba por obrigá-la a adotar - nas palavras de um dos entrevistados - uma "lógica produtivista", embora se possa, ainda, manter "propostas curriculares diferenciadas". Esse produtivismo, lembra outro entrevistado, insere-se numa perspectiva de consolidação da própria universidade, na medida em que se trata de uma instituição em construção.

Com a destinação de $50 \%$ de suas vagas para alunos estrangeiros, a internacionalização do ensino é vista por seu corpo gestor e parte de seu corpo docente como uma forma de - dentro do espírito que rege uma instituição popular - promover esse relacionamento sul-sul, na medida em que a maior parte de seu alunado estrangeiro teria como procedência o continente africano, perspectiva já presente no próprio nome da universidade. Trata-se, na visão de um dos entrevistados, de uma atitude de natureza política, uma vez que se optou, institucionalmente, pela aproximação com um continente histórica e tradicionalmente colocado à margem das relações internacionais estabelecidas pelo Brasil, fato que implica, segundo outro entrevistado, observar até mesmos questões do cotidiano escolar, como o idioma ou a alimentação do alunado.

Mas não apenas a internacionalização contaria a favor de um processo - embora um tanto difuso - de "popularização" do ensino superior, mas também sua contraface, a regionalização. Com efeito, com um contingente de discentes provenientes da macrorregião do maciço do Baturité que ultrapassa a metade de seu alunado, a UNILAB contribui significativamente para o processo de interiorização do ensino superior, privilegiando, assim, uma formação visceralmente vinculada às questões regionais e seus problemas.

\footnotetext{
${ }^{4}$ Entrevistas realizadas no âmbito do já citado projeto "Observatório da Universidade Popular no Brasil", no campus de Redenção, com os responsáveis pelas Pró-Reitora de Extensão, Arte e Cultura; Pró-Reitoria de Graduação; Pró-Reitora de Pesquisa e Pós-Graduação; Pró-reitoria de Políticas Afirmativas Estudantis e PróReitoria de Relações Institucionais, além de uma professora de um dos cursos de graduação da instituição. Agradeço a Neide Cristina da Silva, do PPGE da Universidade Nove de Julho, pela transcrição e organização das referidas entrevistas, bem como pelo resumo de algumas das falas transcritas.

\begin{tabular}{l|l|l|l|l} 
(C) Rev. Inter. Educ. Sup. & Campinas, SP & v.4 & n.1 & p.112-129
\end{tabular} jan./abr. 2018
} 
Tais pressupostos e práticas não dispensam um esforço incomensurável no sentido de aperfeiçoar mecanismos de inclusão do alunado "marginalizado" pelas estruturas hegemônicas de poder (das quais, diga-se de passagem, a universidade em geral faz parte), buscando enfrentar desafios de toda ordem. Um exemplo desses desafios, alerta-nos um dos entrevistados, é a necessidade de alcançar, nos países africanos com quem a universidade estabelece relação de parceria, as regiões mais periféricas, já que o contato com esses países é feito via embaixadas, as quais, por motivos óbvios, localizam-se nos grandes centros urbanos e nas capitais. Outro desafio lembrado é a necessidade de se criarem cursos tradicionalmente frequentado por classes sociais privilegiadas, como o curso de medicina, área da qual, aliás, a região é particularmente carente. No campo da extensão, busca-se, por exemplo, uma maior integração com a comunidade local, priorizando projetos que envolvam a sociedade civil da região e valorizando saberes regionais, que vão de encontros com artesãs de Redenção até a apresentação de capoeira jogada pelos grupos do maciço de Baturité.

Dois temas caros a qualquer universidade que, nos moldes do que aqui estamos considerando como popular, possa ser classificada como tal não poderiam deixar de ser contemplado nas entrevistas realizadas: a gestão participativa e o currículo.

Em relação ao primeiro, gestores entrevistados afirmam haver participação democrática em suas instâncias e procedimentos de gestão, muito em razão da proximidade física entre a equipe gestora da universidade e o grupo de docentes e discentes. Sobretudo o acesso franqueado à reitoria é elogiado por pelo menos um dos entrevistados, além da discussão colegiada da construção do currículo dos cursos. Em relação ao segundo tema, justamente o currículo, destacam-se a continuada discussão dos programas curriculares dos cursos e a existência de um núcleo comum de disciplinas para todos os cursos (que um dos entrevistados denominou como disciplinas "de formação humanista"), a despeito de um citado "conflito de interesses em relação aos conteúdos" entre alunos brasileiros e estrangeiros, o que, a rigor, coloca em suspeição parte da arquitetura da integração que sustenta, institucionalmente, a universidade. Outros aspectos do quadro curricular, contudo, são elogiados incondicionalmente, como o fato de o curso de agronomia ter sido criado pensando na agricultura familiar: "ele é todo organizado nesta perspectiva, inclusive todo o processo de estágio dos nossos estudantes envolve esse acompanhamento [...] $\mathrm{E}$ [em relação às] disciplinas, o maior diferencial é que elas têm uma interdisciplinaridade muito grande, tem teoria e prática ao mesmo tempo", afirma um dos entrevistados.

Talvez o tema mais delicado de todo o processo de constituição de uma universidade popular diga respeito à formação/atuação de seu professorado. Com efeito, no caso aqui analisado, percebe-se que o processo de seleção do corpo docente continua sendo o tradicional, uma vez que esse processo é regido por normas externas à própria universidade. Segundo os entrevistados, contudo, os novos ingressantes passam, nas palavras de um de seus gestores, "por um processo de adaptação e conseguem, de certa forma, se adequar as necessidades da

\begin{tabular}{l|l|l|l|l|l}
\hline (C) Rev. Inter. Educ. Sup. & Campinas, SP & v.4 & n.1 & p.112-129 & jan./abr. 2018 \\
\hline
\end{tabular}


Unilab". Relativamente externa à universidade é também a avaliação institucional, embora se reconheça as especificidades da universidade, motivo pelo qual se propugna por mudanças no processo avaliativo.

O caso das políticas de inclusão merece consideração à parte: adotaram-se, na instituição, as cotas pelo fator público e as cotas raciais; além disso, existe uma pró-reitoria especialmente voltada para as ações afirmativas, com a criação de um núcleo de estudos afro-brasileiro e africanos e um núcleo de gênero e sexualidades; finalmente, em relação à permanência do estudante, a universidade aderiu ao PNAES (Programa Nacional de Assistência Estudantil), sendo que, segundo seus gestores, $86 \%$ dos estudantes são beneficiados pelo programa.

\section{CONSIDERAÇÕES FINAIS}

É sabido que, de modo geral, o sistema universitário brasileiro apresenta distorções crônicas, resultantes de seu caráter historicamente elitista, patrimonialista e excludente. Essa realidade é facilmente percebida em processos como o de acesso à educação superior, em geral altamente seletivo; além disso, ideologicamente, o sistema universitário brasileiro baseia-se na equivocada noção de meritocracia e, não, na de igualdade de direito ou na de justiça igualitária. Trata-se, por isso mesmo, de uma distorção estrutural (mas cujos fundamentos provêm de um poder superestrutural), que se traduz, em geral, numa prática pouco democrática, já denunciada há bastante tempo (FERNANDES, 1975; RISTOFF, 2011).

Destacando os fatores que aqui consideramos próprios de uma universidade popular, a partir de uma bibliografia previamente definida, percebemos que, no caso da UNILAB, há ainda muito o que se fazer, embora os primeiros passos nesse sentido parecem ter sido dados. Tanto do ponto de vista epistemológico quanto dos metodológico e político, podem-se verificar alguns avanços, mas práticas tradicionalistas ainda persistem, possivelmente como legados de uma estrutura burocrática que rege, ainda, nossa estrutura educacional superior. Os maiores ganhos, nesse campo, parecem mesmo estar nas políticas de inclusão, sobretudo inclusão étnico-racial, para a qual a UNILAB certamente já tem dado uma significativa contribuição (COSTA, 2016), além, evidentemente, do vínculo com a comunidade local, talvez uma de suas principais marcas (GOMES; LERCHE, 2013), integração, aliás, que parece estar na origem do desenvolvimento da própria região (RIBEIRO; RUSSO, 2012).

Embora este estudo resulte, grosso modo, numa perspectiva "positiva" do papel desempenhado pela UNILAB no contexto dos modelos "alternativos" de educação superior, há que se ressalvar o fato de que a referida instituição encontra-se, ainda, num estágio de consolidação de métodos e procedimentos educacionais, carecendo de estudos mais aprofundados e extensos acerca de seus fundamentos ideológicos, bem como de seus vínculos 
com processos políticos mais amplos, como o Tratado de Bolonha (SIEGER, 2010; ROCHA; VAIDERGORN, 2010). ${ }^{5}$

De qualquer maneira, a questão da UNILAB - aqui estudada, sobretudo, em sua relação com problemas de natureza étnico-racial - insere-se na discussão mais ampla do ensino e das universidades públicas. Nesse sentido, propugnamos pelo ideal de que urge fazer de nossas universidades públicas instituições que se configurem, tanto na teoria quanto na prática, em modelos realmente democráticos de ensino superior, que, ademais, vão além do conceito funcionalista de universidades estatais, isto é, não apenas instituições superiores em que o Estado funcione como um gestor, atuando dentro de uma lógica excludente, mas em que o Estado, além de geri-las, atue como mediador/regulador de fato, incentivando e promovendo um amplo e contínuo processo de inclusão, democratização e popularização do conhecimento.

\section{REFERÊNCIAS}

ALEXANDRE, Suelen de Pontes. A inclusão da diversidade no Ensino Superior: um estudo da Universidade Federal da Integração Latino-Americana (UNILA) na perspectiva das epistemologias contra-hegemônicas. 2015. Dissertação (Mestrado em Educação) Universidade Nove de Julho, São Paulo, 2015.

ALMEIDA-FILHO, Naomar de. Rankings, Vikings, Master \& Colleges: dilemas da universidade brasileira no contexto da internacionalização. In: VILLAR, José Luiz \& CASTIONI, Remi. Diálogos entre Anísio e Darcy. O projeto da UnB e a educação brasileira. Brasília: Verbena, 2012, p. 218-244.

BENINCÁ, Dirceu; SANTOS, Eduardo. O caráter popular da educação superior. In: SANTOS, Eduardo; MAFRA, Jason Ferreira; ROMÃO, José Eustáquio (org.). Universidade Popular: teorias, práticas e perspectivas. Brasília: Liber Livro, 2013, p. 51-79.

BISSERET, Noëlle. Les inégaux ou la sélection universitaire. Paris: Presses Universitaires de France, 1974.

BRANDÃO, Carlos Rodrigues; ASSUMPÇÃO, Raiane. Cultura Rebelde. Escritos sobre a Educação Popular Ontem e Agora. São Paulo: Instituto Paulo Freire, 2009.

BRASIL. Decreto n. ${ }^{\circ}$ 4228, de 13 de maio de 2002. Institui, no âmbito da Administração Pública Federal, o Programa Nacional de Ações Afirmativas e dá outras providências. Diário Oficial da União, Brasília, DF, 14 mai. 2002. Disponível em: < http://www.palmares.gov.br/wp-content/uploads/2010/11/legis07.pdf > . Acesso em 22 maio 2017.

\footnotetext{
${ }^{5}$ Buscando dar conta do que aqui denominamos fundamentos ideológicos da UNILAB, tem sido desenvolvida sob nossa orientação -, pela mestranda Francisca Mônica Rodrigues de Lima, pesquisa intitulada "Vozes e contravozes de um discurso universitário lusófono: o caso da UNILAB".

\begin{tabular}{l|l|l|l|l|l} 
(C) Rev. Inter. Educ. Sup. & Campinas, SP & v.4 & n.1 & p.112-129 & jan./abr. 2018 \\
\hline
\end{tabular}
}


BRASIL. Ministério da Educação. Diretrizes curriculares nacionais para a educação das relações étnico-raciais e para o ensino de história e cultura afro-brasileira e africana. Brasília: MEC/SEPPIR, 2004.

BUARQUE, Cristovam. A aventura da universidade. São Paulo; Rio de Janeiro: Unesp; Paz e Terra, 1994.

BUSSILLET, Dominique. Les universités populaires au Portugal et au Brésil. In: POULOUIN, Gérard (Org.). Universités populaires hier et aujourd'hui. Paris: Autrement, 2012, p. 274-281.

CHIZZOTTI, Antonio. Pesquisa em Ciências Humanas e Sociais. São Paulo: Cortez, 1991.

COSTA, Elisangela André da Silva. Universidade da Integração Internacional da Lusofonia Afro-Brasileira (UNILAB): contribuições para a educação das relações étnico-raciais. In: CAPRINI, Aldieris Braz Amorim (Org.). Educação e diversidade étnico-racial. Jundiaí: Paco, 2016, p. 109-130.

DIÓGENES, Camila Gomes; AGUIAR, José Reginaldo (Org.). UNILAB: Caminhos e Desafios Acadêmicos da Cooperação Sul-Sul. Redenção: Unilab, 2013.

FERNANDES, Florestan. Universidade Brasileira: Reforma ou Revolução? São Paulo: Alfa-Ômega, 1975.

FERNANDES, Florestan. O negro no mundo dos brancos. São Paulo: Global, 2007.

FREIRE, Paulo. Cartas à Guiné-Bissau. Registros de uma Experiência em Processo. Rio de Janeiro: Paz e Terra, 1977.

FREIRE, Paulo. Pedagogia do Oprimido. Rio de Janeiro: Paz e Terra, 2010.

GADOTTI, Moacir. Universidade popular dos movimentos sociais: breve história de um sonho possível. Disponível em: < http://www.universidadepopular.org/media/relatos \%20oficinas/Gadotti.pdf >. Acesso em 02 abr 2017.

GADOTTI, Moacir; STANGHERLIM, Roberta. A universidade na perspectiva da educação popular. In: SANTOS, Eduardo; MAFRA, Jason Ferreira; ROMÃO, José Eustáquio (Org.). Universidade popular: teorias, práticas e perspectivas. Brasília: Liber Livro, 2013, p. 19-49.

GOMES, Nilma Lino; LERCHE, Sofia. Construindo uma ponte Brasil-África: a Universidade da Integração Internacional da Lusofonia Luso-Afrobrasileira (UNILAB). Revista Lusófona de Educação, Universidade Lusófona de Humanidades e Tecnologia, Lisboa, No. 24: 75-88, 2013.

GONÇALVES, Luiz Alberto Oliveira. Negros e educação no Brasil. In: LOPES, Eliane Marta Teixeira; FILHO, Luciano Mendes Faria; VEIGA, Cynthia Greive (Org.). 500 anos de educação no Brasil. Belo Horizonte: Autêntica, 2003, p. 325-346.

\begin{tabular}{l|l|l|l|r|r}
\hline (c) Rev. Inter. Educ. Sup. & Campinas, SP & v.4 & n.1 & p.112-129
\end{tabular}
jan./abr. 2018 
GUIMARÃES, Antonio Sérgio Alfredo. Ações afirmativas para a população negra nas universidades brasileiras. In: SANTOS, Renato Emerson dos; LOBATO, Fátima (Org.). Ações Afirmativas. Políticas Públicas contra as Desigualdades Sociais. Rio de Janeiro, DP\&A, 2003, p. 76-82.

LAKATOS, Eva Maria; MARCONI, Marina de Andrade. Fundamentos de Metodologia Científica. São Paulo: Atlas, 2001.

LOSS, Adriana Salete; KRATOCHVIL, Claudia Finger. Universidade popular - um sonho possível de ser concretizado. In: BAUER, Carlos; ROGGERO, Rosemary; LORIERI, Marcos Antônio (Org.). Pedagogias Alternativas. Jundiaí: Paco, 2014, p. 359-372.

MASON, Jennifer. Qualitative Researching. London: Sage Publications, 2002.

NÓBREGA, Evangelita Carvalho da. Ações afirmativas na universidade popular brasileira: o caso da Universidade Federal do Sul da Bahia. 2016. Dissertação - (Mestrado em Educação) - Universidade Nove de Julho, São Paulo, 2016.

RIBEIRO, Fabrício Américo; RUSSO, José Figueira. Arranjos e práticas especiais em Redenção-CE: a Unilab como promotora do desenvolvimento local. Educare. Revista Científica do Colégio Militar de Fortaleza, Fortaleza, Ano 5, No. 6: 91-98, out. 2012.

RISTOFF, Dilvo. A universidade brasileira contemporânea: tendências e perspectivas. In: MOROSINI, Marília Costa (Org.). A universidade no Brasil: concepções e modelos. Brasília: INEP, 2011, p. 23-35.

ROCHA, Cíntia Lins; VAIDERGORN, José. Processo de Bolonha: a criação de um espaço europeu de ensino superior e possíveis influências nas universidades brasileiras. Revista Ibero-Americana de Estudos em Educação, Araraquara, v. 5, n. 2, p.1-08, 2010. Disponível em: <file:///C:/Users/USER/Downloads/3476-8691-2-PB\%20(1).pdf>. Acesso em 18 mai 2017.

ROMÃO, José Eustáquio; LOSS, Adriana Salete. A universidade popular no Brasil. In: MACEDO, Eunice (Org.). Fazer educação, fazer política. Linguagem, resistência e ação. Porto: Legis, 2014, p. 37-61.

ROMÃO, Tatiana Alves. A inclusão da diversidade na educação superior: estudo exploratório da proposta político-pedagógica da Universidade Federal da Integração LatinoAmericana. 2015. Dissertação - (Mestrado em Educação) - Universidade Nove de Julho, São Paulo, 2015.

SADER, Emir. Perspectivas. Os porquês da desordem mundial. Rio de Janeiro: Record, 2005.

SANTOS, Boaventura de Sousa. Renovar a teoria crítica e reinventar a emancipação social. São Paulo: Boitempo, 2007.

\begin{tabular}{|l|l|l|l|l|l} 
(C) Rev. Inter. Educ. Sup. & Campinas, SP & v.4 & n.1 & p.112-129 & jan./abr. 2018 \\
\hline
\end{tabular}


SANTOS, Boaventura de Sousa. A universidade no século XXI: para uma reforma democrática e emancipação da Universidade. São Paulo: Cortez, 2010.

SANTOS, Eduardo \& SILVA, Maurício. Equidade e Igualdade na Reconfiguração da Educação Superior Brasileira - Governo FHC e Lula. Poiésis. Revista do Programa de PósGraduação em Educação. Universidade do Sul de Santa Catarina, Santa Catarina, Vol. 6, No. 10, 2012. Disponível em:

<http://www.portaldeperiodicos.unisul.br/index.php/Poiesis/article/view/1319>. Acesso em 23 ago 2017.

SARAMAGO, José. Democracia e universidade. Belém/Lisboa: Edufpa/Fundação José Saramago, 2013.

SGUISSARDI, Valdemar. Universidade no Brasil: dos modelos clássicos aos modelos de ocasião?. In: MOROSINI, Marília Costa (Org.). A universidade no Brasil: concepções e modelos. Brasília: INEP, 2011, p. 275-289.

SIEGER, Ralf Hermes. O Processo de Bolonha e os novos espaços transnacionais de educação superior latino-americanos: a universidade brasileira em movimento. Cadernos PROLAM/USP - Brazilian Journal of Latin American Studies, São Paulo, Universidade de São Paulo, v.9, n.2, p.119-135, 2010. Disponível em:

<http://www.usp.br/prolam/downloads/2010_2_7.pdf>. Acesso em 20 maio 2017.

SILVA, Adailton et al. Entre o racismo e a desigualdade: da construção à promoção de uma política de igualdade racial (1988-2008). In: JACCOUD, Luciana (Org.). A construção de uma política de promoção da igualdade racial: uma análise dos últimos 20 anos. Brasília: IPEA, 2009, p. 19-92.

SILVA, Cidinha da. Definições de metodologias para seleção de pessoas negras em programas de ação afirmativa em educação. In: SILVA, Cidinha da (Org.). Ações afirmativas em educação: experiências brasileiras. São Paulo: Summus, 2003, p. 39-61.

SILVA, Maria Lúcia da. Memória dos professores negros da UNILAB: tecendo saberes e práxis. 2016. Tese - (Doutorado em Educação) - Universidade Nove de Julho, São Paulo, 2016.

TAVARES, Manuel. A universidade e a pluralidade epistemológica: a construção do conhecimento em função de outros paradigmas epistemológicos não ocidentocêntricos. Revista Lusófona de Educação, Universidade Lusófona de Humanidades e Tecnologia, Lisboa, n. 24: 49-74, 2013.

VIEIRA, Sofia Lerche. A democratização da universidade e a socialização do conhecimento. In: FÁ VERO, Maria de Lourdes (Org.). A universidade em questão. São Paulo: Cortez; Autores Associados, 1989, p. 11-26. 


\section{${ }^{1}$ Sobre o autor}

Maurício Silva

E-mail: maurisil@gmail.com / ORCID: http://orcid.org/0000-0002-9609-4579

Universidade Nove de Julho - Brasil

Doutor em Letras Clássicas de Vernáculas - Universidade de São Paulo 